\title{
Building performance implications of occupant mobility
}

\author{
Sara Gilani ${ }^{1}$, Rhys Goldstein ${ }^{2}$, Simon Breslav ${ }^{2}$, Alex Tessier ${ }^{2}$, William O’Brien ${ }^{1}$ \\ ${ }^{1}$ Department of Civil and Environmental Engineering, Carleton University, Ottawa, Canada \\ ${ }^{2}$ Autodesk Research, Toronto, Canada
}

\begin{abstract}
In the ongoing effort to improve building performance predictions, a key question is whether it is important to consider variations of occupant distributions resulting from inter-zone occupant mobility inside a building. The objective of this research is to study the impact of various occupant distributions on building performance predictions using simulation. A generic office building in Toronto, Canada, was simulated under homogeneous and heterogeneous distributions of occupants using EnergyPlus. The simulation results showed that as occupant mobility inside a building led to varied occupants' densities at the zone level, zone-level energy use and unmet hours are dependent on occupant mobility.
\end{abstract}

\section{Introduction}

In the common building performance practice, occupants are assumed to be distributed uniformly in buildings. That is, occupant densities are generally kept consistent between timesteps and across similar spaces. In reality, however, occupants move between spaces (e.g. for meetings) and therefore distributions of occupants may vary temporally and spatially.

Assuming a uniform distribution of occupants may affect building performance predictions such as energy demand and heating and cooling loads (Wang et al. 2018). For instance, Wang et al. (2017) showed that energy demand can be reduced by $20 \%$ compared to a common control system using the dynamic spatial occupants' distribution matrix that they developed. Likewise, Zhang et al. (2017) extracted probabilistic distribution functions for the spatial diversity in internal heat gains using data collected from various tenants in seven office buildings. Their validation study in one of their case studies showed that the calculated cooling load was $36 \%$ higher than what the simulation results suggested (based on the probabilistic distribution functions that they developed) and 39\% higher than the measured cooling load in that building.

Additionally, interior layouts evolve over the building life-cycle, often with implications for occupant distributions and densities. For instance, Goldstein et al.'s (2011) modeling technique showed the potential for using space layout in predicting occupants' locations and activities. As a consequence of spaces' layout evolution, building systems and equipment may not be capable of meeting heating or cooling loads.
To improve building performance predictions regarding heterogeneous occupant distributions, previous research developed methods to simulate these conditions in building performance simulation (BPS) tools. For instance, Yan and Jiang (2005) and Yan et al. (2008) proposed a method to calculate a range of operations, rather than a specific value, in order to consider different internal heat gains in building performance simulation. However, the impact of occupant mobility within a building on its performance in the design process using BPS tools is not evident yet.

To evaluate the impact of occupant mobility on building performance predictions, the occupant modeling method in BPS tools is an important factor. Wang et al. (2011) and its application-based tool Occupancy Simulator (Chen et al. 2018) developed a Markov model to simulate the stochasticity in occupants' location in buildings. Similarly, Hong et al. (2016) used a Markov model to predict the probability of occupants' locations. However, there are still gaps in the literature with respect to how to model inter-zone occupant mobility for building energy simulation and knowledge on the importance of the impact of occupant mobility on building performance predictions.

To address these gaps, the current research develops a simulation-based method for studying inter-zone occupant mobility inside a building. The potential building performance implications (i.e. energy use and unmet hours) of neglecting occupant mobility (i.e. temporal and spatial distributions) between building spaces are studied as well. Note that in this context, "mobility" pertains to the variations in the distribution of occupants in spaces of a single building over time. In other words, if an occupant leaves one zone in a building, that occupant goes to another zone in that building.

The main objective of this paper is to provide a proof of the concept that occupant mobility between zones of a building affects its performance. To this end, this research first developed a simulation-based method and then, used it for testing the concept. In the present simulation-based analysis, occupants were assumed to move between building spaces just because of office work-related purposes (e.g. individual meetings, group meetings, conference, breaks/lunch) rather than to restore their comfort.

The building model and simulation-based methodology developed in the current research are first explained. 
Afterwards, the simulation results are discussed, followed by outlining conclusions, limitations, and future work.

\section{Building model}

A medium reference office building, located in Toronto, Canada, based on the standard assumptions (National Research Council Canada 2015) was simulated using BPS tool EnergyPlus. The office building, with the total floor area of $4982 \mathrm{~m}^{2}$, consisted of 15 thermal zones: one core zone and four perimeter zones on each floor (Figure 1). HVAC sizing was calculated at the beginning of each annual simulation run based on the design days. During HVAC sizing periods, it was assumed that occupants were evenly distributed (i.e. standard assumptions). Table 1 presents a summary of the building model specifications.

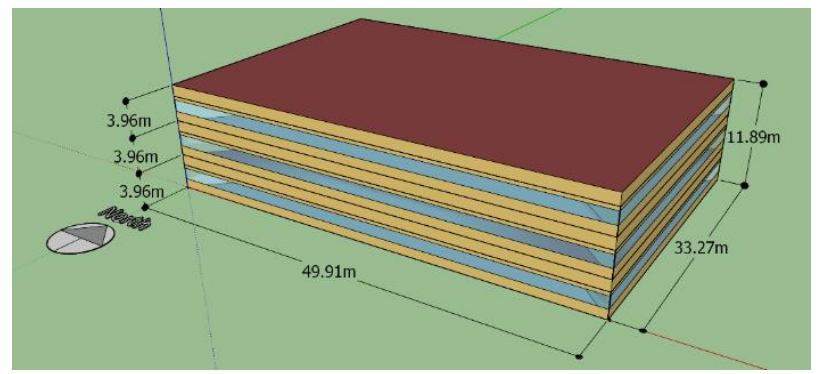

Figure 1. Geometry of building model.

\section{Methodology}

The building model was simulated under homogeneous distributions of occupants for one annual run and under heterogeneous distributions of occupants for 50 annual runs. Standard schedules were used in simulating both homogeneous and heterogeneous distributions of occupants. To investigate the potential performance implications of neglecting inter-zone occupant mobility in a building, the number of occupants in each zone of the building model was generated randomly using a normal distribution at the beginning of each weekday. Note that a key difference between Wang et al.'s (2011) model and the current methodology is that the former predicts occupant location based on the previous timestep using Markov chain simulation method, whereas the current approach uses a simpler approach and considers daily variation in occupants' locations. In the current methodology, it is assumed that occupants choose their locations at the beginning of each weekday in open-plan offices with unassigned desks. Moreover, the total number of occupants in the building at each timestep is kept consistent between the homogeneous and heterogeneous distributions of occupants to emulate their mobility inside the building which has a specific number of zones; whereas Wang et al.'s (2011) model does not impose any constraints on occupant and zone numbers.

Figure 2 shows the flowchart of the procedure for generating daily random number of occupants on weekdays and weekends. Assuming $20 \mathrm{~m}^{2} /$ person as per standard assumptions (National Research Council Canada 2015), the peak total number of occupants (i.e. 249) was calculated with respect to the area of about 984, 207, and $131 \mathrm{~m}^{2}$ for the core, south or north, and east or west zones, respectively. The maximum number of occupants in each zone was randomly generated using the methodology summarized in Figure 2. The maximum number of occupants was multiplied hourly by the occupancy standard schedule in each space. Note that as per standard assumptions, occupancy schedule used for weekends was different from the one used for weekdays to take account of lower occupancy on weekends. Based on National Research Council Canada (2015), office spaces are unoccupied on weekends, whereas they are partially occupied on weekdays (mainly between 8 AM and 6 PM). Note that negative values generated by normal distribution for number of occupants were truncated to zero. Non-integer numbers of occupants were rounded to the nearest integer. To avoid a widely spread or narrow distribution of the generated number of occupants, the standard deviation was set to be equal to the mean of the number of occupants. Previous studies (e.g. Duarte et al. 2013; D'Oca and Hong 2015) also showed that occupancy patterns in office spaces is highly variable. Figure 3 presents examples of the weekday profile of the number of occupants generated using the methodology.

The methodology for generating the daily random number of occupants in each zone (see Figure 2) was implemented in the Energy Management System feature of EnergyPlus. Occupants' use of electric equipment was assumed to be correlated with their presence in each zone using a simplified method (Mahdavi et al. 2016). Assuming the peak electric equipment power as $72 \mathrm{~W} /$ person based on the peak loads observed in open-plan offices (Mahdavi et al. 2016), peak electric equipment power (W/person) was multiplied hourly by the electric equipment standard schedule and number of occupants in each space. Note that the number of occupants was set to the peak number of occupants (i.e. without multiplying it by the corresponding occupancy schedules) for the calculation of the electric equipment power in each zone. Figure 4 presents the weekday profile of the electric equipment power intensity generated using the methodology.

Lights of each zone were assumed to be on whenever at least one occupant was present in that zone, otherwise lights were off. Outdoor air rates were calculated based on the occupancy at each timestep assuming the air loop was capable of achieving demand-controlled ventilation. The simulation timestep was set to 10 minutes. 
Table 1. Summary of building model specifications based on National Research Council Canada (2015).

\begin{tabular}{|c|c|c|}
\hline \multirow{3}{*}{$\begin{array}{l}\text { Building envelope } \\
U \text {-factor }\left[W / \mathbf{m}^{2} \mathbf{K}\right]\end{array}$} & Roof & 0.18 \\
\hline & Wall & 0.27 \\
\hline & Floor & 0.67 \\
\hline \multirow{3}{*}{ Glazing system } & $U$-factor $\left[\mathrm{W} / \mathrm{m}^{2} \mathrm{~K}\right]$ & 2.2 \\
\hline & SHGC & 0.60 \\
\hline & $V T$ & 0.21 \\
\hline \multicolumn{2}{|l|}{ HVAC air loop } & Three air handling units (AHUs), one for each floor. \\
\hline \multicolumn{2}{|l|}{ Space heating } & $\begin{array}{l}\text { A primary and secondary boiler with the thermal efficiency of } 0.8 \text { using natural } \\
\text { gas. Independently controlled VAV boxes with reheat coils on each floor. } \\
\text { Independently controlled hot water baseboard heaters in each zone for } \\
\text { supplementary heating. }\end{array}$ \\
\hline \multicolumn{2}{|l|}{ Space cooling } & $\begin{array}{l}\text { A primary and secondary chiller model of EIR with a reference COP of } 4.5 \text {. } \\
\text { Three economizers, one for each AHU, controlled outdoor air based on } \\
\text { comparing the enthalpy of return and outdoor air. }\end{array}$ \\
\hline \multicolumn{2}{|c|}{ Mechanical ventilation } & $\begin{array}{l}\text { Minimum ventilation rates of } 2.5 \mathrm{~L} / \mathrm{s} . \text { person and } 0.3 \mathrm{~L} / \mathrm{s} . \mathrm{m}^{2} \text { as per ASHRAE } \\
\text { Standard } 62.1(2016) \text {. }\end{array}$ \\
\hline \multicolumn{2}{|l|}{ Infiltration } & $0.0002 \mathrm{~m}^{3} / \mathrm{s} . \mathrm{m}^{2}$ exterior surface area. \\
\hline \multicolumn{2}{|c|}{ Heating and cooling setpoints } & $\begin{array}{l}\text { Heating and cooling setpoints were set to } 22 \text { and } 24^{\circ} \mathrm{C} \text {, respectively, from } 8 \mathrm{AM} \\
\text { to } 8 \mathrm{PM} \text { on weekdays. They were set back to } 18 \text { and } 35^{\circ} \mathrm{C} \text { at } 10 \mathrm{PM} \text { as per } \\
\text { National Research Council Canada (2015). }\end{array}$ \\
\hline
\end{tabular}

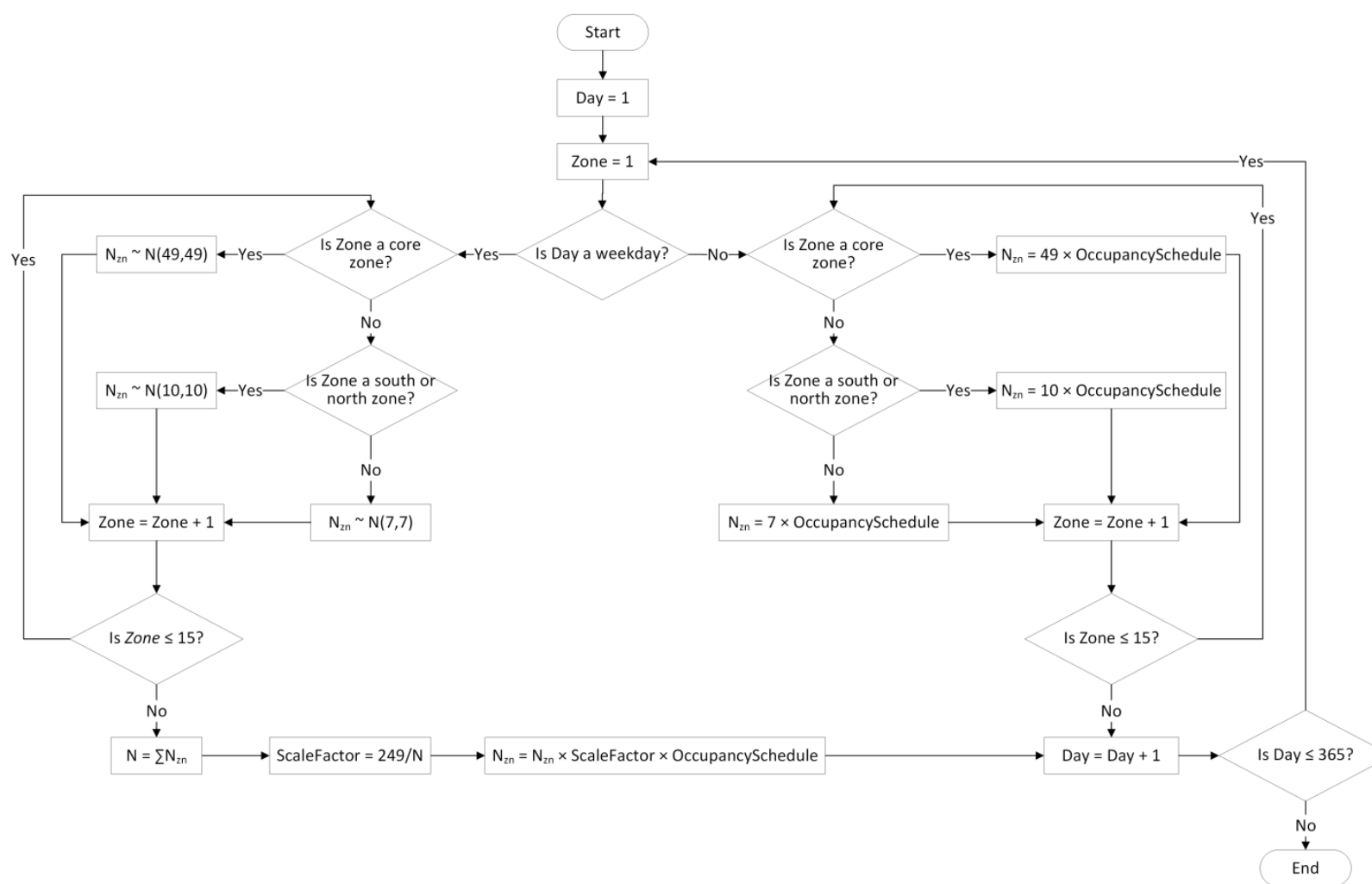

Figure 2. Procedure for generating daily random number of occupants in each zone of the building model on weekdays and weekends. Note that the occupancy schedule used for weekdays differs from the occupancy schedule used for
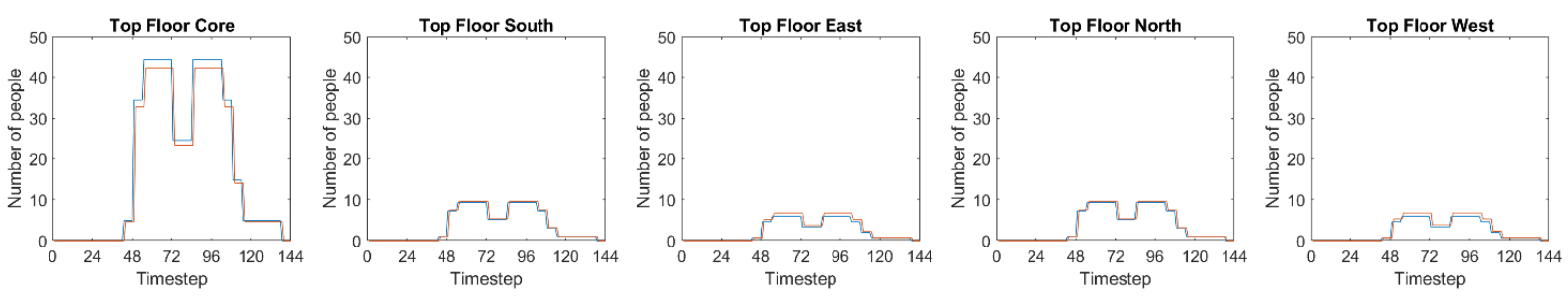

Figure 3. Examples of weekday profile of number of occupants with and without considering occupant mobility based on the annual simulation runs. 

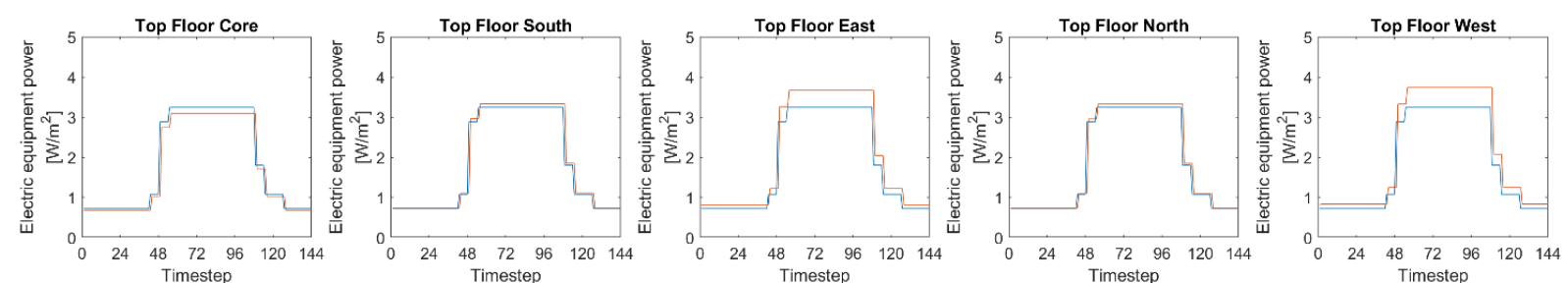

Figure 4. Examples of weekday profile of electric equipment power with and without considering occupant mobility based on the annual simulation runs.

\section{Results and discussion}

The potential building performance implications of neglecting varying occupant distributions in the building model were extracted from the simulation outputs. This section presents the simulation results of the variations between when inter-zone occupant mobility was considered and when it was neglected for the considered performance measures.

\section{Energy use}

Figure 5 presents the annual results of the average natural gas energy use for heating and electricity energy use for cooling, lights, electric equipment, fans, and pumps as well as the annual occupied-zone fraction.

Note that the occupied-zone fraction, to measure whether a zone was occupied, is calculated using Equation (1):

$$
\overline{\text { OccFrac }}=\frac{\sum_{\mathrm{zn}=1}^{\mathrm{n}_{\mathrm{zn}}} \sum_{\mathrm{ts}=1}^{\mathrm{n}_{\mathrm{ts}}}\left\{\begin{array}{lr}
1, & \text { if } \mathrm{Min}_{\text {NumberOfOccupants }}=1 \\
0, & \text { otherwise }
\end{array}\right.}{\mathrm{n}_{\mathrm{zn}} \times \mathrm{n}_{\mathrm{ts}}}
$$

where $\overline{\text { OccFrac }}$ is the average occupied-zone fraction across 15 zones; $z n$ is the considered zone; $n_{z n}$ is the number of zones (i.e. 15 zones); $t s$ is the timestep; $n_{t s}$ is the number of timesteps (i.e. 52,560); and Min $_{\text {NumberOfOccupants }}$ is the minimum number of occupants who are present in the zone.

Figure 5 indicates that considering occupant mobility led to a reduction of $22 \%$ in the lighting electricity energy use and $16 \%$ in the average occupied-zone fraction. The reduction in the average occupied-zone fraction is due to the fact that the times when a zone was unoccupied or in overcrowded conditions with considering occupant mobility was more than when occupant mobility was neglected.

The simulation results showed that the total occupied duration (i.e. the time when at least one occupant was present in a zone) averaged across 15 zones was 4160 hours when occupant mobility inside the building was neglected, whereas it was 3506 hours (averaged across 15 zones) when occupant mobility was considered. Assuming lights were on whenever at least one occupant was present in a zone, otherwise lights were off, resulted in the total lights-on duration of 3506 hours averaged across 15 zones (equal to the occupied hours) when occupant mobility was considered, whereas the lights were on all the time (with varied fraction of full capacity) based on the standard assumptions.

The reduction in the lighting electricity energy use and occupied-zone fraction resulted in that the heating system was working for longer with considering occupant mobility compared to neglecting occupant mobility. Consequently, the pumps, which were operating intermittently, were on for longer and their electricity energy use increased (by about 7\%).

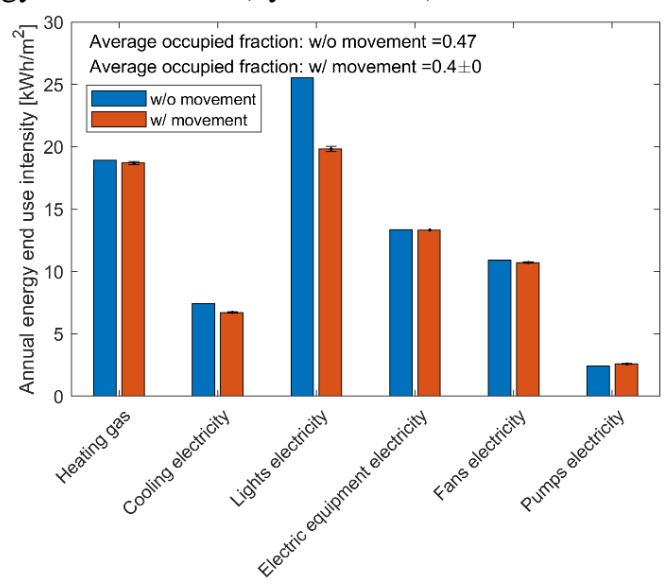

Figure 5. Annual energy use intensity with and without considering occupant mobility.

The cumulative distribution of the predicted annual peak cooling and heating loads at the building and floor level are presented in Figures 6 and 7. Note that studying spatial diversity in peak loads is important for the sizing of building-level equipment (e.g. a central chiller or boiler) and zone-level HVAC systems (e.g. AHU, VAV boxes) (Zhang et al. 2017). In the current study, the annual peak cooling or heating loads at the building level were calculated based on the sum of the cooling or heating loads of all the zones at each timestep. Similarly, the annual cooling or heating loads at the floor level were calculated based on the sum of the cooling or heating loads of the corresponding zones at each floor. Figures 6 and 7 show the impact of when occupant mobility was considered versus when it was neglected for building equipment sizing.

The simulation results show that the annual heating energy use values with and without considering occupant mobility were almost identical (see Figure 5), whereas the peak heating load was considerably affected when occupant mobility was considered (see Figure 6). This observation is due to the fact that the annual number of occupants in the zones with and without considering occupant mobility followed the same trend, while the number of occupants with and without considering occupant mobility varied on a daily temporal scale which affected the peak heating load.

Figure 6 shows that considering occupant mobility led to the increase of $1 \%$ in the peak cooling loads and $17 \%$ in 
the peak heating loads of the building model at the confidence level of $95 \%$ compared to when occupant mobility was neglected. Similarly, Figure 7 shows that considering occupant mobility led to the increase in the predicted peak floor-level heating and cooling loads at the confidence level of $95 \%$. The increase in the predicted annual peak cooling load of the bottom, middle, and top floors is about 5,6 , and $5 \%$, respectively; whereas, the increase in the predicted annual peak heating load of the bottom, middle, and top floors is about 11,15 , and $21 \%$, respectively. The results of the predicted peak cooling and heating loads indicated that the heating loads were more affected by considering occupant mobility as the building model was simulated in a heating-dominated climate and using electric equipment was set based on the number of occupants in a zone.

As shown in Figure 7, the discrepancy in the predicted annual peak heating load of the top floor between when occupant mobility was considered and neglected was higher than the bottom floor by a factor of two. This observation indicates the potential impact of neglecting occupant mobility at various spatial scales. Moreover, taking account of variations in occupant distributions, which resulted from occupant mobility, affected building energy use temporally. Figure 8 presents the temporal variations in the predicted heating power intensity between $8 \mathrm{AM}$ and $6 \mathrm{PM}$ on weekdays in the five zones of the top floor between when occupant mobility was considered (averaged across 50 runs) and when it was neglected. The results of the heating power intensity on the top floor showed that it varied from zero to $56 \mathrm{~W} / \mathrm{m}^{2}$ when occupant mobility was considered compared to when it was neglected.
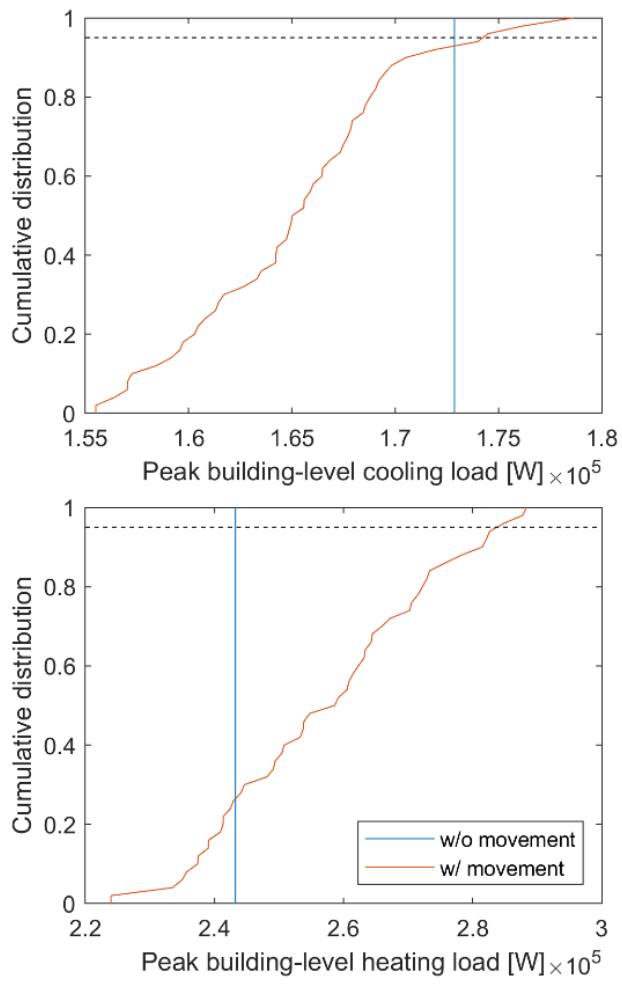

Figure 6. Cumulative distribution of annual peak cooling and heating loads of the building model at the building level. Blue lines represent when occupant mobility was neglected, and red line represents the distribution of the results when occupant mobility was considered. Dashed lines represent the confidence level of $95 \%$.
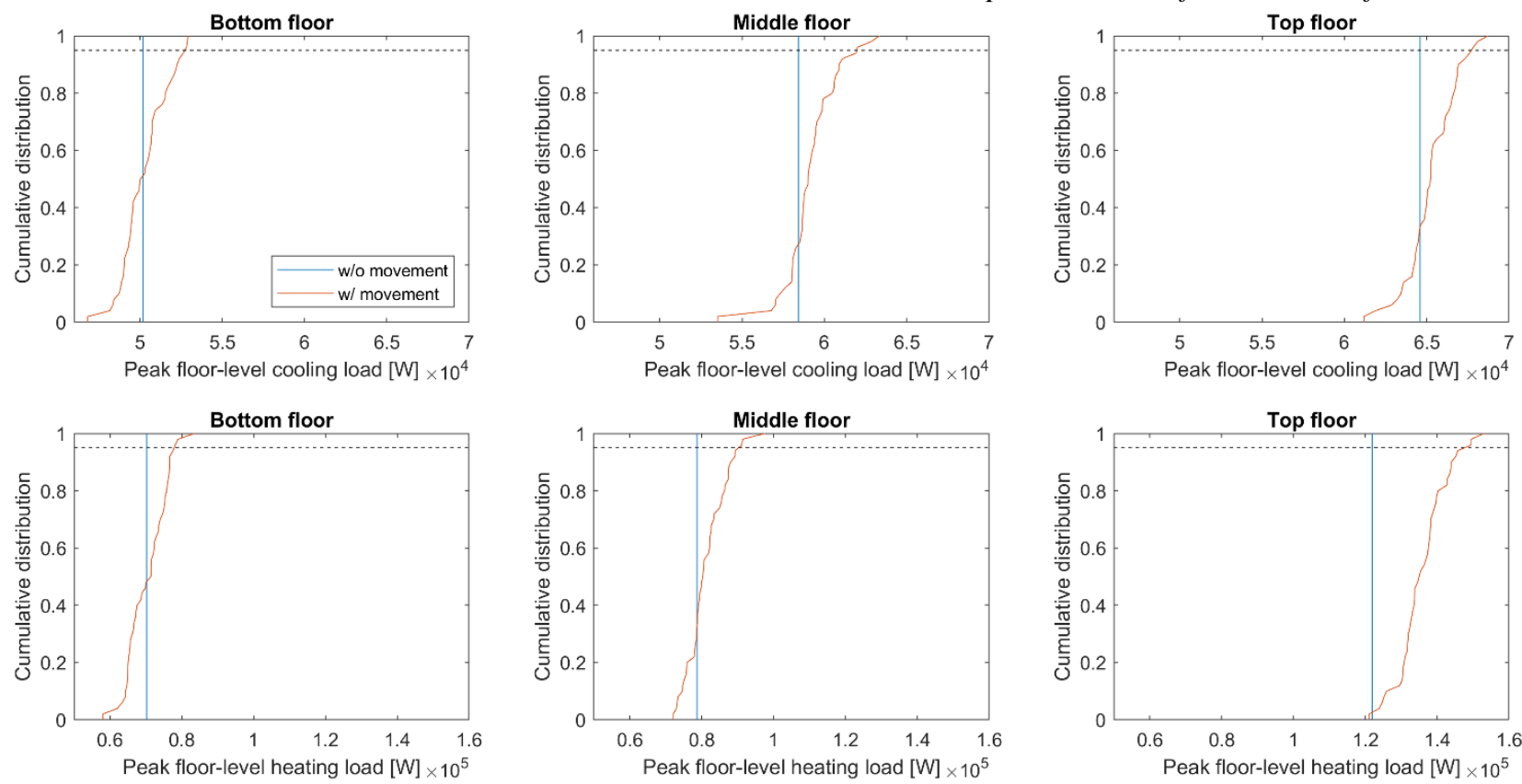

Figure 7. Cumulative distribution of annual peak cooling and heating loads of the building model at the floor level. Blue lines represent when occupant mobility was neglected, and red line represents the distribution of the results when occupant mobility was considered. Dashed lines represent the confidence level of $95 \%$. 


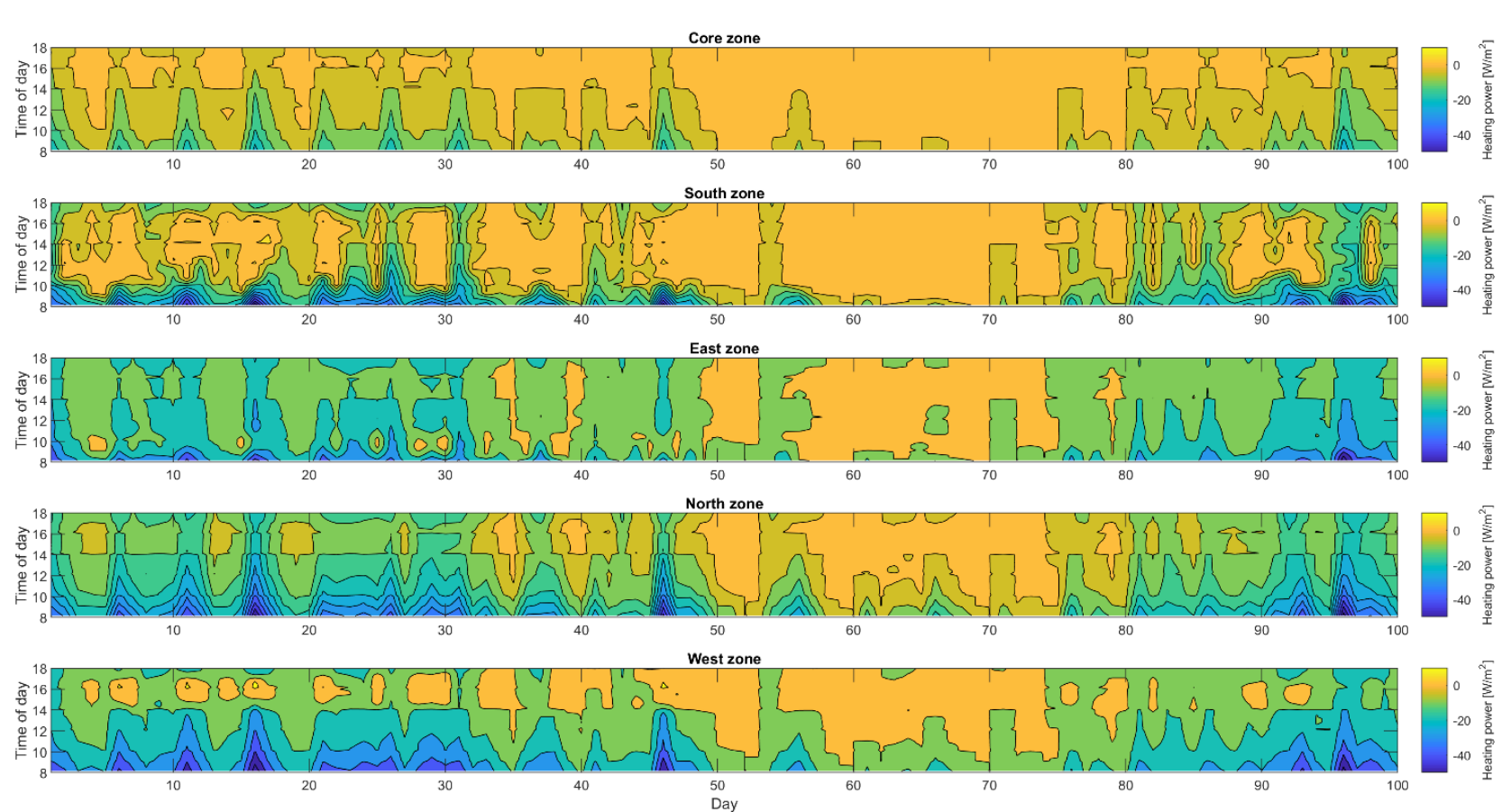

Figure 8. Temporal and spatial difference between when occupant mobility was considered (averaged across 50 runs) and when it was neglected in the predicted heating power intensity $\left(\mathrm{W} / \mathrm{m}^{2}\right)$ between 8 AM and 6 PM on weekdays in the five zones of the top floor.

\section{Unmet hours}

As explained previously, the present study assumed that occupants moved between rooms in a building for officerelated work rather than to improve their comfort. This section explains the results of the impact of considering occupant mobility on the number of hours when the heating or cooling setpoints were not met. To this end, the building-level unmet hours was calculated. As per ASHRAE Standard 90.1's (2016) definition, the whole building has an unmet hour even if a single zone of the building has an unmet hour. On the basis of this definition, in the current study, the building-level unmet hours was calculated from $8 \mathrm{AM}$ to $6 \mathrm{PM}$ on weekdays when occupants were present in a zone. The building-level unmet cooling setpoint hours was 148 hours when occupant mobility was neglected, whereas it was 292 hours when occupant mobility was taken into account. As any of the zones may be overcrowded with considering occupant mobility, the unmet cooling setpoint hours with occupant mobility was higher compared to when occupant mobility was neglected.

Figure 9a shows the annual unmet cooling setpoint hours (NotMetSetpoint) at the zone level which was calculated without weighting by the number of occupants who were present in a zone where the cooling setpoint was unmet from $8 \mathrm{AM}$ to $6 \mathrm{PM}$ on weekdays. This value is calculated using Equation (2):

$$
\text { NotMetSetpoint(zn) }=\frac{\mathrm{TS}}{60} \times \sum_{\mathrm{ts}=1}^{\mathrm{n}_{\mathrm{ts}}} \begin{cases}1, & \text { if } \operatorname{Min}_{\mathrm{N}}=1 \\ 0, & \text { otherwise }\end{cases}
$$

where $T S$ is the timestep in minutes (i.e. 10 minutes) and $\operatorname{Min}_{N}$ is the minimum number of occupants who are present in a zone where the heating or cooling setpoint is unmet.
Note that NotMetSetpoint neglects the number of occupants who were present in a zone, however considering number of affected occupants is more critical when inter-zone occupant mobility is taken into account. To consider number of occupants who may be affected by discomfort conditions, the unmet cooling setpoint hours weighted by the number of occupants (NotMetSetpoint $_{\text {Weighted }}$ ) was calculated as well (Figure $9 \mathrm{~b})$. This measure indicates the annual number of hours when the cooling setpoint in each zone was unmet which is weighted by the number of occupants who were present in a zone where the cooling setpoint was unmet from 8 AM to 6 PM on weekdays. This value is calculated based on Equation (3):

$$
\text { NotMetSetpoint }_{\text {Weighted }}(\mathrm{zn})=\frac{\mathrm{TS}}{60} \times \sum_{\mathrm{ts}=1}^{\mathrm{n}_{\mathrm{ts}}} \frac{\mathrm{N}}{\sum_{\mathrm{zn}=1}^{\mathrm{n}_{\mathrm{zn}} \mathrm{N}}}
$$

where $N$ is the number of occupants who are present in a zone where the heating or cooling setpoint is unmet.

As noted earlier, the HVAC equipment sizing was calculated using the standard assumptions (i.e. when inter-zone occupant mobility was not considered) at the beginning of each annual simulation run based on the design days. Since it was assumed that there were no internal heat gains from occupants, lights, and electric equipment on the winter design day, the unmet heating setpoint hours was zero when inter-zone occupant mobility was considered similarly to when it was neglected. However, the unmet cooling setpoint was affected considering occupant mobility as the internal heat gains were set as the highest values for the summer design day based on the standard assumptions; whereas when occupant mobility was considered and consequently, occupants may crowd into a zone, the cooling demand of that zone may not be met. 
Figure 9 indicates that the total NotMetSetpoint Weighted $_{\text {S }}$ averaged across 50 runs increased by a factor of two and the total NotMetSetpoint averaged across 50 runs increased by a factor of 1.7 when occupant mobility was considered compared to when it was neglected. This trend indicates that occupant mobility led to higher occupants' densities and higher unmet hours.

(a)

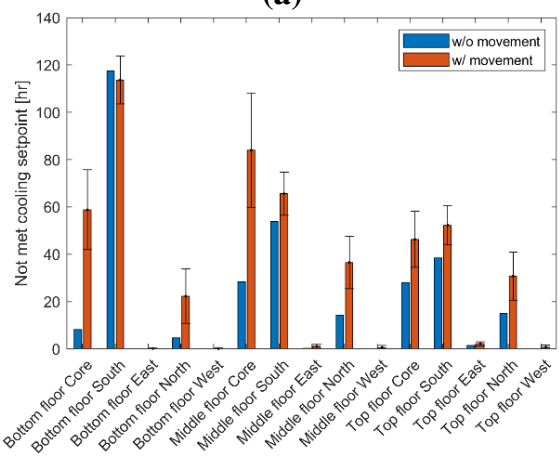

(b)

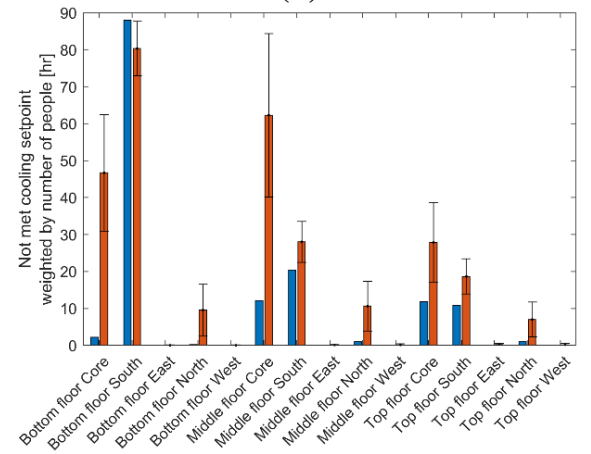

Figure 9. Annual number of hours when the cooling setpoint in each zone was unmet: (a) not weighted, and (b) weighted by number of occupants who were present in a zone where the cooling setpoint was unmet.

To test whether considering occupant mobility had a significant impact on the weighted unmet cooling setpoint hours, the paired-sample $t$-test was used. For each of the paired samples (i.e. each of the 15 zones in the building model), the variables were the weighted unmet cooling setpoint hours with and without considering occupant mobility. As there were 15 paired samples, the degree of freedom was 14 . The weighted unmet cooling setpoint hours averaged across the 15 zones was $9.8 \mathrm{hr}$ without considering occupant mobility, whereas it was $19 \mathrm{hr}$ with considering occupant mobility. The null hypothesis was that considering occupant mobility did not cause a significant impact on the weighted unmet cooling setpoint hours. The paired sample $t$-test rejected the null hypothesis with the $p$-value of 0.04 (assuming the standard significance level of 0.05). In other words, the weighted unmet cooling setpoint hours considering occupant mobility was in general significantly higher than when inter-zone occupant mobility was neglected.

To find the cause of unmet cooling setpoint hours, the total internal heat gains from lights and electric equipment, number of occupants, and transmitted solar radiation during unmet cooling setpoint hours were calculated. Figure 10 shows that the total number of occupants and the total lighting and electric equipment energy use during unmet cooling setpoint hours increased when occupant mobility was considered compared to when it was neglected.

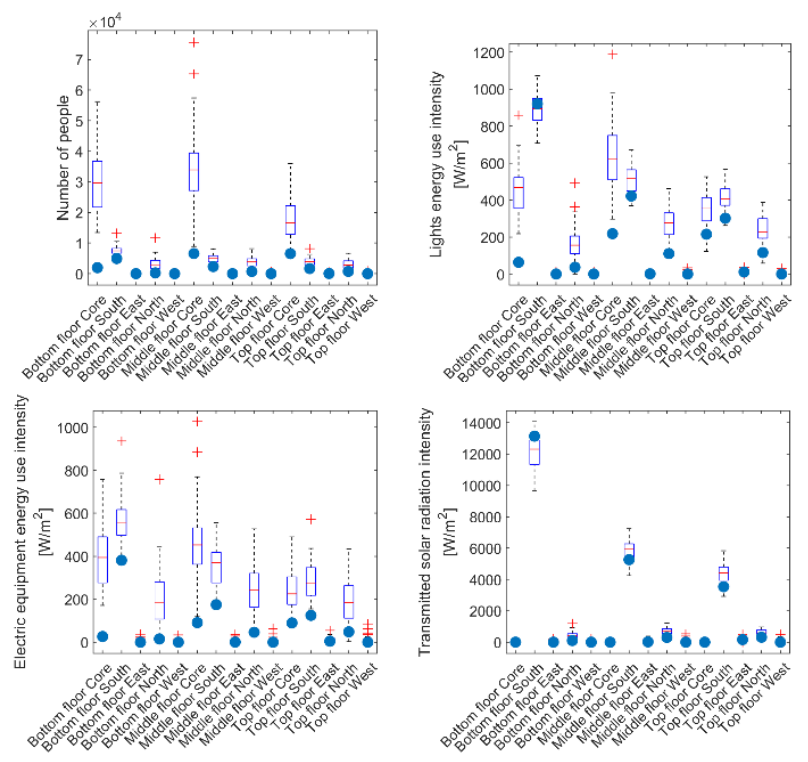

Figure 10. Total number of occupants and total energy use intensity from lights, electric equipment, and transmitted solar radiation during unmet cooling setpoint hours in each zone with and without considering occupant mobility. Blue dots represent when occupant

mobility was neglected, and boxplots represent the distribution of the results when occupant mobility was considered (distribution of 50 annual simulation runs).

The paired-sample $t$-test was used on the paired samples (i.e. each of the 15 zones in the building model) to test if the internal heat gains and transmitted solar radiation were significantly different during unmet cooling setpoint hours with and without considering occupant mobility. The analysis on the internal heat gains and transmitted solar radiation during unmet cooling setpoint hours using the paired-sample $t$-test revealed that while transmitted solar radiation was not significantly different with and without considering occupant mobility, the internal heat gains from occupants, lights, and electric equipment were significantly different when occupant mobility was taken into account compared to when it was neglected (Table 2).

Table 2. Paired-sample t-test on the total number of occupants and total energy use intensity from lights, electric equipment, and transmitted solar radiation in the 15 zones during unmet cooling setpoint hours with and without considering occupant mobility.

\begin{tabular}{|l|c|c|}
\hline \multicolumn{1}{|c|}{ Output } & Hypothesis test result* & $\boldsymbol{p}$-value*** \\
\hline Number of occupants & 1 & 0.04 \\
\hline $\begin{array}{l}\text { Lighting energy use } \\
\text { intensity }\end{array}$ & 1 & 0.01 \\
\hline $\begin{array}{l}\text { Electric equipment } \\
\text { energy use intensity }\end{array}$ & 1 & 0.00 \\
\hline $\begin{array}{l}\text { Transmitted solar } \\
\text { radiation intensity }\end{array}$ & 0 & 0.27 \\
\hline
\end{tabular}

* One indicates that the $t$-test rejected the null hypothesis and zero indicates that it did not reject the null hypothesis.

** At the 5\% significance level. 


\section{Conclusion and future work}

This research developed a simulation-based method for the evaluation of inter-zone occupant mobility within a building to study the impact of homogeneous and heterogeneous distributions of occupants on building performance. The simulation results showed that since occupant mobility caused variations in occupant distributions at the zone level, zone-level energy consumption and unmet hours were dependent on occupant mobility. This study indicates the importance of knowing detailed distributions of occupants. The discrepancies observed in this research resulting from neglecting inter-zone occupant mobility in building performance simulation are the potential ones, whereas accurate occupant distributions necessitate a statistically large sample of real-world case studies. As this information may not be available for new constructions in building design process, the authors recommend looking at multiple scenarios.

This research had limitations that requires future work. While the findings of the present research demonstrated the importance of considering occupant mobility on building performance predictions, the impact of occupant mobility on building performance requires real-world data as a future necessary methodology of this research topic. In this study, occupants' comfort was not considered as the reason for their movement between zones, however considering comfort as a trigger for occupant mobility necessitates future research. The results of this research are based on the defined HVAC system and this specific building design and type in a specific climate zone. It was assumed that demand-controlled ventilation was possible with the current HVAC configuration. Furthermore, in the present research, it was assumed that the normal distribution is appropriate for determining the random number of occupants in various zones of the building model, while this assumption requires further research based on real data. A simple approach was implemented for internal gains from electric equipment. It was also assumed that lights were on or off for an entire zone.

Our future work is to apply our methodology to a variety of building control systems and types in various climate zones to determine conditions where neglecting interzone occupant mobility has a lower or higher impact on building performance. For example, considering occupant mobility is of high importance where occupant-based (either active or passive) building control systems are incorporated in buildings. Different assumptions about building and zone-level control systems (e.g. lights and HVAC terminal units), relationship between occupants' presence and electric equipment use, and in-depth investigation into energy use, unmet hours, and discomfort in individual rooms within a zone are our future work regarding the current research topic.

\section{References}

ANSI/ASHRAE Standard 62. 1. (2016). ANSI/ASHRAE Standard 62.1 - Ventilation for acceptable indoor air quality. American Society of Heating, Refrigeration and Air-Conditioning Engineers.
ASHRAE. (2016). ANSI/ASHRAE/IES Standard 90.1 Energy standard for buildings except low-rise residential buildings. American Society of Heating, Refrigeration and Air-Conditioning Engineers.

Chen, Y., Hong, T., and Luo, X. (2018). "An agent-based stochastic Occupancy Simulator." Building Simulation, 11(1), 37-49.

D’Oca, S., and Hong, T. (2015). "Occupancy schedules learning process through a data mining framework." Energy and Buildings, 88(Supplement C), 395-408.

Duarte, C., Van Den Wymelenberg, K., and Rieger, C. (2013). "Revealing occupancy patterns in an office building through the use of occupancy sensor data." Energy and Buildings, 67(Supplement C), 587-595.

Goldstein, R., Tessier, A., and Khan, A. (2011). "Space layout in occupant behavior simulation." 1073-1080.

Hong, T., Sun, H., Chen, Y., Taylor-Lange, S. C., and Yan, D. (2016). "An occupant behavior modeling tool for co-simulation." Energy and Buildings, 117, 272281.

Mahdavi, A., Tahmasebi, F., and Kayalar, M. (2016). "Prediction of plug loads in office buildings: Simplified and probabilistic methods." Energy and Buildings, 129, 322-329.

National Research Council Canada. (2015). National Energy Code of Canada for Buildings 2015.

Wang, C., Yan, D., and Jiang, Y. (2011). "A novel approach for building occupancy simulation." Building Simulation, 4, 149-167.

Wang, W., Chen, J., and Hong, T. (2018). "Modeling occupancy distribution in large spaces with multifeature classification algorithm." Building and Environment, 137, 108-117.

Wang, W., Chen, J., Huang, G., and Lu, Y. (2017). "Energy efficient HVAC control for an IPS-enabled large space in commercial buildings through dynamic spatial occupancy distribution." Transformative Innovations for a Sustainable Future - Part II, 207, 305-323.

Yan, D., and Jiang, Y. (2005). "HVAC system simulation and analysis based on uncertain inner heat gains."

Yan, D., Xia, J., Tang, W., Song, F., Zhang, X., and Jiang, Y. (2008). "DeST — An integrated building simulation toolkit Part I: Fundamentals." Building Simulation, 1(2), 95-110.

Zhang, Q., Yan, D., An, J., Hong, T., Tian, W., and Sun, K. (2017). "Spatial distribution of internal heat gains: A probabilistic representation and evaluation of its influence on cooling equipment sizing in large office buildings." Energy and Buildings, 139, 407-416. 